\title{
The Effects of Pine Needles Biocomposites Floor Mats on Consumers Tactile Perception of Comfort during Sitting on the Floor while Eating at a Restaurant
}

\author{
Hatif Adiar Almantara ${ }^{1}$, Prabu Wardono ${ }^{2}$, Meirina Triharini ${ }^{3}$ \\ ${ }^{1}$ Faculty of Art and Design ITB, Indonesia \\ ${ }^{2}$ Faculty of Art and Design ITB, Indonesia \\ ${ }^{3}$ Faculty of Art and Design ITB, Indonesia \\ *Corresponding author. Email: hatifalmantara@gmail.com
}

\begin{abstract}
"Floor sitting" is part of the culture of several countries in Asia. Utilizing the waste pine needles to become biocomposites floor mats could make something unique and perhaps it could stimulate human sensory during sitting on the floor while eating at a restaurant. The purpose of this research is to measure the quality of the tactile perception to feel comfort by sitting on the floor while eating using the pine needles biocomposites mats. Then the experiment was held to examine the pine needles biocomposites to the reaction of the respondents. There were six types of sitting mats, four types of them were the pine needles biocomposites were made based on different surface textures (smooth - rough) and also density levels (loose - dense), the rest types were the existing mats as the control variable. For the result of the experiment, it was noted that the pine needles biocomposites mats can affect the floor sitting comfort of the consumer while they are eating at the restaurant these days by its texture and looks. The pine needles biocomposites mats are predominant to tactile comfort and visual aspect compared to the existing mats. For the result of the examined comfort, the respondents feel more comfortable when they sat on the pine needles biocomposites mats with the smooth surface and loose density type than other types. Most respondents feel safe and convenient with the texture because the net covers its surface.
\end{abstract}

Keywords: Pine needle, Biocomposite, Tactile perception, Floor sitting

\section{INTRODUCTION}

Sitting is a natural human posture. Many human activities are conducted in a sitting position. The sitting manner in each area is influenced by the existing culture. In the Asian region, various traditional sitting positions were practiced long before Western furniture was introduced and usually performed on the floor. The floor is where humans began learning to move from being on their prone lying, sitting, crawling, to walking. When noticed, the human body is not designed for chairs [1]. The floor sitting culture is found in several countries in Asia, such as Arab, India, China, Korea, Japan, Malaysia, and Indonesia. In Indonesia, especially in Java, the culture is known as "lesehan". The Indonesians traditionally still sit on the floor when eating or doing other activities in the house. They had tended to sit most comfortably on the floor before Western influences introduced the dining table [2].

Most Indonesian restaurants carrying traditional concepts, such as Javanese or Sundanese, apply a floor sitting scheme (lesehan) as part of their facilities. Traditional life cannot be separated from the existence of the surrounding natural elements. Basically, humans have an intuition to be close to nature. Humans and the natural environment are two things that cannot be separated because they are interconnected and beneficial to each other. The current trend in the world of design and architecture is looking for new ways to establish connections with nature. Much of this is motivated by environmental 
awareness [3]. One way to bring natural elements into the interior is by using environmentally friendly materials, such as biocomposites from natural waste. Biocomposite is an alternative material with the potential to be used as a material for making furniture. Biocomposite characters derived from natural materials are unique due to their shape, texture, and form. The uniqueness of these characters becomes a stimulus for the human sensory perception that can create new sensations of experience, especially for the sensory perception of touch. Thus, the experience sensation can provide comfort while sitting on the floor.

This research refers to the theory and previous research regarding biocomposite and the physical comfort of sitting and its psychological aspect. Biocomposite production needs to go through several processes. In his research, Lilholt [4] explained the biocomposites making process, which begins with a forming fibers process by using short fibers. The fibers are then arranged regularly or randomly into sheets, which are then mixed with polymers, such as polyethylene/polypropylene, until they are evenly distributed on each side of the fiber. The fiber sheets are then pressed and heated at a certain pressure and temperature between $110^{\circ} \mathrm{C}$ and $200^{\circ} \mathrm{C}$. The melted polymer will bind natural fibers to form a composite sheet.

Various factors influence the quality of comfort when sitting. According to Hänel [5], contact pressure, pressure distribution, and loading time are the main parameters affecting the mechanical comfort. The comfort is assessed by the stimulus applied to the seat material. In his research, Motavalli [6] stated that the comfort of sitting facilities depends on the distribution of pressure over the contact area between the subject and the object, including sitting on a biocomposite seat.

The tactile comfort stimulus formation for sitting on biocomposite materials has resulted from the comfort parameter elaboration. The relation between sitting comfort and touch perception refers to Tiest's [7] research in 2010 regarding the perception of touch on material properties. He revealed that the material's properties include roughness related to the height differences on the material's surface, compliance related to material's elasticity (hard-soft), coldness (temperature) related to the material's heat capacity and thermal conductivity, and slipperiness related to the friction between the material and the skin. From this statement, it can be formulated that the variable of tactile comfort when sitting is influenced by roughness, hardness, and material temperature.
The stimulus in the form of hardness differences is related to the material elasticity. The elasticity can be perceived through the surface deformation, vibrations, and force/displacement information [7]. The user's sitting posture influences the pressure distribution on the seat. Based on the type of sitting posture on the floor expressed by Hewes [8] and Wiyancoko [9], this study assessed four types of floor sitting postures, namely sitting cross-legged (sila), sideways (simpuh samping), kneeling (simpuh), and knees up (jegang). The difference in the hardness level of the seat material object is obtained from the density manipulation of the biocomposite material.

The time-related mechanical comfort parameter is related to the time length of a person sitting on an object. The longer he/she sits on the seat, the hotter it will be. Heat and humidity conditions on the seat are influenced by the respondent's body metabolism while sitting. According to Scilingo [10], based on previous research conducted by Lederman and Klatzky, the hardness, together with texture and thermal conductivity is information that is processed after the initial contact. Thus, thermal can be felt sometime after the initial contact. The thermal condition difference is assessed by comparing the seat conditions at the beginning and the end-after being sat for a long time.

According to Desmet [11], an object or product can be felt with sensory organs (touch, taste, and smell) and directly becomes a source of pleasure or displeasure. Emotional stimulation in a product is obtained by feeling the product (seeing, touching, hearing, and smelling), using the product (the event itself), and the consequences of using the product. Emotional theory often distinguishes three kinds of attention, namely attitudes, goals, and standards. Based on the source, product emotions are judged from intrinsic comfort, consistency motive, and legitimacy. Intrinsic comfort applies to the three emotional stimuli because the product is an object, and all objects (including their properties and characteristics) can be appraised whether they are comfortable or not.

This study aims to measure the comfort quality of the floor-sitting touch perception towards the eating behavior. Comfort is an important requirement in conducting activities, including enjoying the food while sitting on the floor. Scientifically, this research can enrich insight and knowledge in innovation, especially in using natural materials like biocomposites. The use of various types of natural materials as new materials to manufacture a product has the potential for further research to be conducted, 
and therefore this research can be a reference for further research in the fields of design, psychology, and culture.

Practically, this research has implications for professions in the design areas. This research on the use of biocomposite materials is an alternative material for interior elements, especially on the floor as a seat. It is hoped that this material innovation can provide positive and new experiences in the world of design. This research will indirectly raise the culture of eating and sitting on the floor with a new sensation of experience. Not only can it be applied to eating in restaurants, but the object of this research can also be applied to other activities. Relaxing in the family room, reading books in the library, doing yoga can be performed by sitting on the floor as the primary posture.

\section{METHOD}

This study uses several experimental methods. The first conducted experiment was the making of pine needles biocomposites. A second experiment was conducted to determine the relationship between the object and the research subjects through testing the pine needles biocomposites seating for the respondents. The selection of respondents is organized by using a convenience sampling technique with youngsters and students as respondents ranging in age from 19-25 years. Students are chosen because they are easily obtainable and included in the restaurant consumers to be selected for research.

In this study, the dependent variable is the comfort factor of the perceived touch. In using a sitting mat, some factors affect a person's comfort, namely the object's mechanical aspects and the respondent's emotions. The mechanical aspects consist of roughness, hardness, and thermal. These aspects are the independent variables in this study. The control variable in this study is the existing material used by most restaurants, providing lesehan areas, in the form of rebonded foam. The variable is used to see the difference between the existing seating materials in most restaurants and the pine needles biocomposites material that has been given a specific stimulus to be tested.

The measuring instrument for the experiment object in this study was a questionnaire. The questionnaire distributed to the respondents was used to determine their profile, floor sitting experience, and comfort level. The questionnaire consisted of three groups of questions, namely section (A) regarding cultural identity and background in the form of written content, section (B) regarding the experience of sitting on the floor (lesehan) in the form of multiple choices, and section (C) regarding the comfort of touch perception in the form of a statement with Likert Scale measurements. This Likert Scale measurement concerns the approval of a statement consisting of five options, namely, (SA) Strongly Agree, (A) Agree, (N) Neutral, (D) Disagree, and (SD) Strongly Disagree. First, the questionnaire as a measuring tool was tested through validity and reliability tests. The data processing of the experimental questionnaire results used statistical tests, namely normality test and parametric test through paired T-test and ANOVA.

\subsection{Experiment 1}

It was conducted to create a stimulus on an object based on the main parameter of sitting comfort expressed by Hänel [4]. Pressure contact is concerned with receiving a stimulus to the surface texture of an object. The pressure distribution is related to the object's elasticity and hardness stimuli in a modified form of the material density. Time relates to the length of time the subject using the object, which causes changes in thermal conditions. As Hänel [4] said, the feeling of comfort depends on the balance of heat flow due to the presence of metabolism, heat energy, and humidity of the subject's body on the object.

In determining the specifications of the studied object, an exploration process is necessary. This process began by calculating the desired density level to determine the initial mass of the pine needles. In addition, it was necessary to determine the type of adhesive that will be used. The adhesive type, considered the most feasible, became the main composition for making biocomposite objects. In this study, the PVAc adhesive was used. After that, the percentage of adhesive and water from the initial mass of pine needles was determined. The production of biocomposites went through the stages of raw material procurement, pine needles drying, weighing, mixing pine needles with adhesives, pressing, and module installation.

Initially, the manipulation used pine needlescut to a size of about $1-2 \mathrm{~cm}$, assuming that the fine texture could be produced from the shorter size of the pine needles. However, biocomposite texture exploration by manipulating the size of pine needles could not achieve the desired density and thickness due to the absence of a cavity in it, which plays a vital role in pressure elasticity and its brittle nature. 
It is an important note that filler dimensions have different properties of strength and elasticity of pressure, even though they have gone through the same calculations and compositions.

The required density in this experiment consisted of two types, namely, $0.05 \mathrm{gr} / \mathrm{cm} 3$ and $0.1 \mathrm{gr} / \mathrm{cm} 3$. The low-density pine needles biocomposite surface is prone to shedding or breaking against friction or movement. To lower the risk, a coating on the biocomposite surface is required. In this research experiment, Fox PC glue (Polychloroprene) was used. This material has an elastic character and is colorless when dry, so it is not visually different from the original condition. The surface texture finishing used in this experiment was divided into two types, namely the original texture of the pine needles biocomposites surface and the biocomposite surface texture with a net textile layer. The net textile material was chosen because, visually, it would still show biocomposite material but give a flatter surface texture. Therefore, it gave a significant difference in the surface texture.

The dimensions of all objects on the sitting mat in this research experiment were $60 \times 60 \times 3 \mathrm{~cm}$. There were two main types of materials, namely pine needles biocomposite (independent variable) and rebonded foam (control variable). Both types of materials were attached to a base with an Ethylenevinyl acetate (EVA) foam material measuring $60 \times 60 \times 0.8 \mathrm{~cm}$ using Fox glue (Polychloroprene Contact Adhesive). The use of the base was intended so that the biocomposite module could be neatly arranged and easy to lift. Then on the outside, a $5 \mathrm{~cm}$ webbing was attached, sewn around each side of the seat mat. The webbing was intended to protect the outer of the biocomposite from being easily damaged.

Table 1. Experimental Object Specifications

\begin{tabular}{|c|c|c|}
\hline Type & Specification & Image \\
\hline A & $\begin{array}{ll}\text { Material } & : \text { Pine needles biocomposites } \\
\text { Density } & : 0.05 \mathrm{gr} / \mathrm{cm}^{3} \\
\text { Composition : Pine needles } 87.5 \mathrm{gr}, \text { PVAc } 52.5 \mathrm{gr}(60 \%) \text {, water } 26.3 \mathrm{gr} \\
\text { Finishing } \quad: \text { Fox PC (Polychloroprene) glue, Net textile }\end{array}$ & \\
\hline B & $\begin{array}{ll}\text { Material } & : \text { Pine needles biocomposites } \\
\text { Density } & : 0.1 \mathrm{gr} / \mathrm{cm}^{3} \\
\text { Composition : Pine needles } 116.38 \mathrm{gr}, \text { PVAc } 46.6 \mathrm{gr}(40 \%) \text {, water } 46.6 \mathrm{gr} \\
\text { Finishing } \quad \text { : Fox PC (Polychloroprene) glue, Net textile }\end{array}$ & \\
\hline C & $\begin{array}{l}\text { Material } \quad: \text { Pine needles biocomposites } \\
\text { Density } \quad: 0.05 \mathrm{gr} / \mathrm{cm}^{3} \\
\text { Composition : Pine needles } 87.5 \mathrm{gr}, \text { PVAc } 52.5 \mathrm{gr}(60 \%) \text {, water } 26.3 \mathrm{gr} \\
\text { Finishing } \quad: \text { Fox PC (Polychloroprene) glue }\end{array}$ & \\
\hline D & $\begin{array}{l}\text { Material } \quad \text { : Pine needles biocomposites } \\
\text { Density }: 0.1 \mathrm{gr} / \mathrm{cm}^{3} \\
\text { Composition : Pine needles 116.38gr, PVAc 46.6gr (40\%), water 46.6gr } \\
\text { Finishing } \quad \text { : Fox PC (Polychloroprene) glue }\end{array}$ & \\
\hline$E$ & $\begin{array}{ll}\text { Material } & : \text { Rebonded foam } \\
\text { Finishing } & : \text { Tissue fabric }\end{array}$ & \\
\hline$F$ & $\begin{array}{ll}\text { Material } & : \text { Rebonded foam } \\
\text { Finishing } & : \text { Tissue fabric }\end{array}$ & \\
\hline
\end{tabular}




\subsection{Experiment 2}

After the research object was ready, the following procedure was testing. Tests were conducted using the lesehan dining area at Roemah Kopi, Bandung, with a low table, dishes, and sitting mats provided as the research objects. The questionnaire was given to respondents according to the type of seat used. Respondents would be asked to sit on top of the object while enjoying a meal and fill out the provided questionnaire for 10-15 minutes. After the first object has been tested, the same steps were taken for the second, third, and sixth objects.

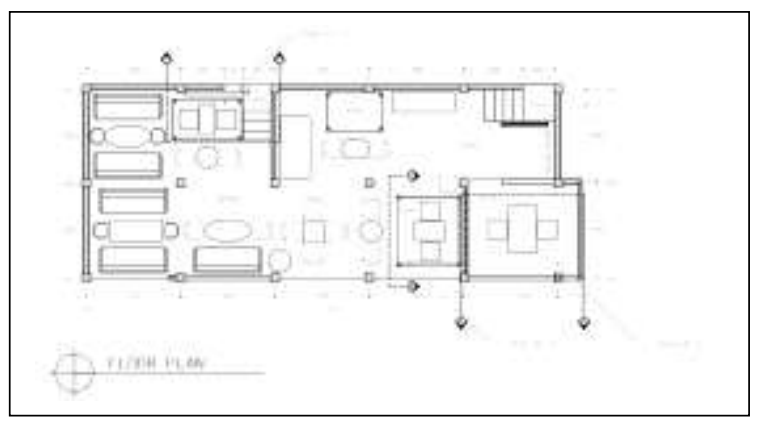

Figure 1. The floor plan of Roemah Kopi's lower floor lesehan area

The experiment was conducted in three lesehan areas located on the lower floor (Figure 1). The three areas were chosen which are not facing each other from one area to another. This was intended to prevent interference or bias in the comfort assessing process of the used seat because the respondent can see other experimental objects before testing. By looking at other experimental objects, it was possible for the respondent to compare the objects he/she used with other objects that he/she did not use. Each selected area was limited by a partition wall so that there was no visual interaction.

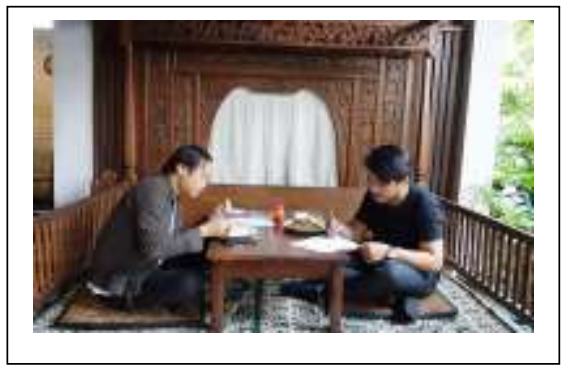

Figure 2. Situation during the experiment in area 2

\section{RESULT AND DISCUSSION}

First, the questionnaire as the measuring instrument test went through validity and reliability tests. The validity test used the opinion of an expert (expert judgment). This research is related to the design and human psychology of products and interiors. Therefore, in testing its validity, it was assisted by a lecturer who is an expert in design psychology to examine the test material to fit the research concept. The validity test was conducted by preparing a blueprint for measuring instruments, used by describing the concepts, indicators, and items. After the measuring instrument blueprint had been made, it was tested on the ten respondents with criteria similar to the actual experimental respondents.

After testing the validity of the measuring instrument, the next step is to test the instrument's reliability to determine its consistency and level of trustworthiness. There were 35 statement items on the questionnaire as measured by the Likert Scale. From the reliability test, it was known that the Cronbach's Alpha coefficient value was $0.892>0.8$, so it can be stated that the reliability was very high. Therefore, the instrument could be used repeatedly with consistent results.

This study involved 31 respondents in the experimental sitting mat testing. The respondents consisted of 19 men and 12 women with an age range of 19-25 years. This was following the target of the research subject, namely the young generation of millennials who are consumers of cafes/restaurants. The respondents had quite a variety of cultural backgrounds. Respondents with Javanese ethnic background became the most dominant by occupying the highest percentage, reaching $29 \%$ or nine people. Within a week, most respondents did their activities by sitting on the floor (lesehan) more than five times, 
with a percentage of $48.4 \%$. The most frequent activity was conducted by most respondents sitting on the floor was eating with a percentage of $26.8 \%$.

Table 2. Kolmogorov-Smirnov Normality Test

One-Sample Kolmogorov-Smirnov Test

\begin{tabular}{|c|c|c|c|c|c|c|c|}
\hline & & TYPE_A & TYPE_B & TYPE_C & TYPE_D & TYPE_E & TYPE_F \\
\hline$\overline{\mathbf{N}}$ & & 31 & 31 & 31 & 31 & 31 & 31 \\
\hline \multirow[t]{2}{*}{ Normal Parameters $^{\text {a,b }}$} & Mean & 122.39 & 118.68 & 113.58 & 113.39 & 111.84 & 110.16 \\
\hline & Std. Deviation & 10.295 & 11.563 & 11.701 & 11.638 & 9.812 & 10.854 \\
\hline \multirow[t]{3}{*}{ Most Extreme Differences } & Absolute & .055 & .152 & .127 & .072 & .085 & .134 \\
\hline & Positive & .055 & .079 & .069 & .065 & .078 & .134 \\
\hline & Negative & -.052 & -.152 & -.127 & -.072 & -.085 & -.067 \\
\hline Test Statistic & & .055 & .152 & .127 & .072 & .085 & .134 \\
\hline Asymp. Sig. (2-tailed) & & $.200^{\mathrm{c}, \mathrm{d}}$ & $.066^{\mathrm{c}}$ & $200^{c, d}$ & $.200^{c, d}$ & $.200^{c, d}$ & $.165^{c}$ \\
\hline
\end{tabular}

The results of the normality test (Table 2) showed that the significance value of 31 respondents in the six types of sitting mats had a significance value $(\mathrm{P}$ value) above 0.05 . The significance values $(\mathrm{P}$ value) were TYPE_A $=0.200$, TYPE_B $=0.066$, TYPE_C $=0.200$, TYPE_D $=0.200$, TYPE_E $=$ 0.200 , and TYPE_F $=0.165$. All TYPEs had a significance value $(\mathrm{P}$ - value $)>0.05$ so that it could be stated that the data were normally distributed.
It was known that the data are normally distributed so that it could be continued with a parametric test. To determine a relationship between variables, it was necessary to test the parametric relationship to use the paired $\mathrm{T}$ test to compare the relationship between 2 variables. This test compares two variables, namely the independent variable, with the control variable. The two control variable objects (TYPE E and TYPE F) have the exact specifications so that testing was only conducted by one object, namely TYPE E.

Table 3. Paired T Test

\begin{tabular}{|c|c|c|c|c|c|c|c|c|c|}
\hline & & \multicolumn{5}{|c|}{ Paired Differences } & \multirow{3}{*}{$\mathbf{t}$} & \multirow{3}{*}{ df } & \multirow{3}{*}{$\begin{array}{l}\text { Sig. (2- } \\
\text { tailed) }\end{array}$} \\
\hline & & \multirow[t]{2}{*}{ Mean } & \multirow[t]{2}{*}{$\begin{array}{c}\text { Std. } \\
\text { Deviation }\end{array}$} & \multirow{2}{*}{$\begin{array}{l}\text { Std. } \\
\text { Error } \\
\text { Mean }\end{array}$} & \multicolumn{2}{|c|}{$\begin{array}{l}\text { 95\% Confidence } \\
\text { Interval of the } \\
\text { Difference }\end{array}$} & & & \\
\hline & & & & & Lower & Upper & & & \\
\hline Pair 1 & $\begin{array}{l}\text { TYPE_A - } \\
\text { TYPE_E }\end{array}$ & 10.548 & 9.906 & 1.779 & 6.915 & 14.182 & 5.929 & 30 & .000 \\
\hline Pair 2 & $\begin{array}{l}\text { TYPE_B - } \\
\text { TYPE_E }\end{array}$ & 6.839 & 10.472 & 1.881 & 2.997 & 10.680 & 3.636 & 30 & .001 \\
\hline Pair 3 & $\begin{array}{l}\text { TYPE_C - } \\
\text { TYPE_E }\end{array}$ & 1.742 & 14.665 & 2.634 & -3.637 & 7.121 & .661 & 30 & .513 \\
\hline Pair 4 & $\begin{array}{l}\text { TYPE_D - } \\
\text { TYPE_E }\end{array}$ & 1.548 & 12.722 & 2.285 & -3.118 & 6.215 & .678 & 30 & .503 \\
\hline
\end{tabular}

The paired T-test results (Table 3) showed that there is a significant difference if the significance value is $<0.05$. On the contrary, if the significance value is $>0.05$, there is no significant difference. The significance value of TYPE A and TYPE E pairs was $0.000<0.05$, so there is a significant difference. Then, the significance value of the TYPE $B$ and TYPE E pairs was $0.001<0.05$, so there was a significant difference. While the TYPE $\mathrm{C}$ and TYPE E pairs had a significance value of $0.513>0.05$, there was no significant difference. Likewise, the TYPE D and TYPE E pairs had a significance value of 0.503 $>0.05$, so there was no significant difference.

The main focus of this research is the factors influencing the comfort of touch when sitting on the floor, namely roughness, hardness, and thermal. These three factors are the parameters for the comfort of sitting on the biocomposite seat. To determine the difference in the level of tactile comfort of all types of sitting mats, the ANOVA test and Post Hoc test were performed. 
Table 4. Tactile comfort ANOVA Test

ANOVA

TOUCH

\begin{tabular}{lrrccr}
\hline & Sum of Squares & df & Mean Square & F & Sig. \\
\hline Between Groups & 2240.113 & 5 & 448.023 & 7.835 & .000 \\
Within Groups & 10292.968 & 180 & 57.183 & & \\
Total & 12533.081 & 185 & & &
\end{tabular}

Table 5. Tactile comfort Post-Hoc Test

LSD

\begin{tabular}{|c|c|c|c|c|c|c|}
\hline \multirow[b]{2}{*}{ (I) TYPE } & \multirow[b]{2}{*}{ (J) TYPE } & \multirow{2}{*}{$\begin{array}{c}\text { Mean } \\
\text { Difference (I-J) }\end{array}$} & \multirow{2}{*}{$\begin{array}{l}\text { Std. } \\
\text { Error }\end{array}$} & \multirow[b]{2}{*}{ Sig. } & \multicolumn{2}{|c|}{ 95\% Confidence Interval } \\
\hline & & & & & Lower Bound & Upper Bound \\
\hline \multirow[t]{5}{*}{ TYPE A } & TYPE B & 3.000 & 1.921 & .120 & -.79 & 6.79 \\
\hline & TYPE C & $8.452^{\star}$ & 1.921 & .000 & 4.66 & 12.24 \\
\hline & TYPE D & $8.258^{\times}$ & 1.921 & .000 & 4.47 & 12.05 \\
\hline & TYPE E & .258 & 1.921 & .893 & -3.53 & 4.05 \\
\hline & TYPE F & 2.000 & 1.921 & .299 & -1.79 & 5.79 \\
\hline \multirow[t]{5}{*}{ TYPE B } & TYPE A & -3.000 & 1.921 & .120 & -6.79 & .79 \\
\hline & TYPE C & 5.452 & 1.921 & .005 & 1.66 & 9.24 \\
\hline & TYPE D & $5.258^{\circ}$ & 1.921 & .007 & 1.47 & 9.05 \\
\hline & TYPE E & -2.742 & 1.921 & .155 & -6.53 & 1.05 \\
\hline & TYPE F & -1.000 & 1.921 & .603 & -4.79 & 2.79 \\
\hline \multirow[t]{5}{*}{ TYPE C } & TYPE A & $-8.452^{*}$ & 1.921 & .000 & -12.24 & -4.66 \\
\hline & TYPE B & $-5.452^{\pi}$ & 1.921 & .005 & -9.24 & -1.66 \\
\hline & TYPE D & -.194 & 1.921 & .920 & -3.98 & 3.60 \\
\hline & TYPE E & $-8.194^{\pi}$ & 1.921 & .000 & -11.98 & -4.40 \\
\hline & TYPE F & $-6.452^{x}$ & 1.921 & .001 & -10.24 & -2.66 \\
\hline \multirow[t]{5}{*}{ TYPE D } & TYPE A & $-8.258^{\star}$ & 1.921 & .000 & -12.05 & -4.47 \\
\hline & TYPE B & $-5.258^{\pi}$ & 1.921 & .007 & -9.05 & -1.47 \\
\hline & TYPE C & .194 & 1.921 & .920 & -3.60 & 3.98 \\
\hline & TYPE E & $-8.000^{\pi}$ & 1.921 & .000 & -11.79 & -4.21 \\
\hline & TYPE F & $-6.258^{x}$ & 1.921 & .001 & -10.05 & -2.47 \\
\hline \multirow[t]{5}{*}{ TYPE E } & TYPE A & -.258 & 1.921 & .893 & -4.05 & 3.53 \\
\hline & TYPE B & 2.742 & 1.921 & .155 & -1.05 & 6.53 \\
\hline & TYPE C & $8.194^{\pi}$ & 1.921 & .000 & 4.40 & 11.98 \\
\hline & TYPE D & $8.000^{\circ}$ & 1.921 & .000 & 4.21 & 11.79 \\
\hline & TYPE F & 1.742 & 1.921 & .366 & -2.05 & 5.53 \\
\hline \multirow[t]{5}{*}{ TYPE F } & TYPE A & -2.000 & 1.921 & .299 & -5.79 & 1.79 \\
\hline & TYPE B & 1.000 & 1.921 & .603 & -2.79 & 4.79 \\
\hline & TYPE C & $6.452^{x}$ & 1.921 & .001 & 2.66 & 10.24 \\
\hline & TYPE D & $6.258^{\star}$ & 1.921 & .001 & 2.47 & 10.05 \\
\hline & TYPE E & -1.742 & 1.921 & .366 & -5.53 & 2.05 \\
\hline
\end{tabular}


*. The mean difference is significant at the 0.05 level.

Based on the results of the ANOVA test and the Post Hoc test, it was known that there was a significant difference in tactile comfort in TYPE C and TYPE D against TYPE A, B, E and F, which were quite significant. To determine the level of this difference, an analysis of the comfort aspect items could be conducted. By looking at the scores, comfort level in each type of sitting mat can be seen.

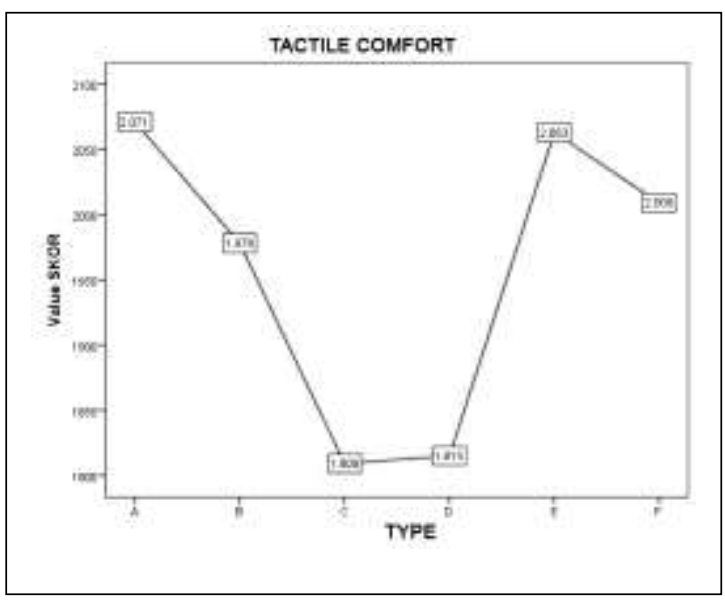

Figure 3. Tactile comfort graphic

Based on the tactile comfort graph in Figure 3, it was known that the highest score for tactile comfort was achieved by TYPE A with a total score of 2.071, while the lowest score was achieved by TYPE $\mathrm{C}$ with a total of 1.809. TYPE E and TYPE $F$ as control variables also had a high enough tactile comfort level. Even though these two control variables scored relatively high, they did not outperform TYPE A, a biocomposite seat cover with a density of $0.05 \mathrm{gr} / \mathrm{cm} 3$ with a layer of netting on its surface.

This research experiment proved Tiest's [7] theory of material properties that roughness is more accessible to feel by respondents than material elasticity in assessing the comfort of touch due to the location of the stimulus on the material's surface. The sitting mat's rough texture disturbed the respondent in feeling the hardness stimulus inside the material. Thermal comfort is influenced by the ability of the material to accommodate long sitting activities. Of course, it is influenced by the quality of the roughness and hardness of the sitting mat material.

The user's sitting posture influences the pressure distribution on the seat. Based on the type of sitting posture on the floor expressed by Hewes [8] and Wiyancoko [9], this study assessed four types of sitting postures on the floor, namely sitting crosslegged (sila), sideways (simpuh samping), kneeling (simpuh), and knees up (jegang). The experimental results show that the most suitable sitting posture for the lesehan eating activity is sitting cross-legged and knees up because it is more stable and more frequently performed in daily activities.

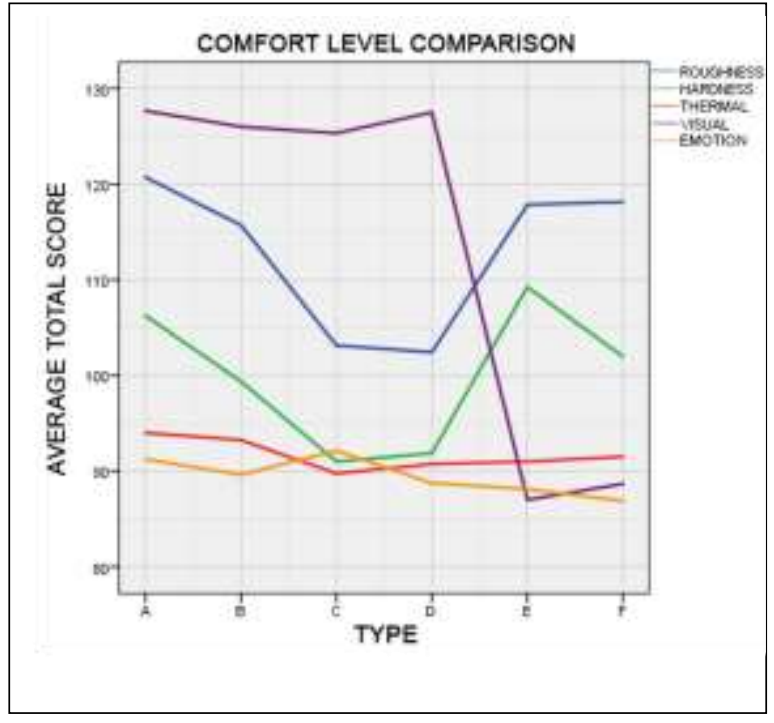

Figure 4. Comfort level comparison chart

Based on the graph in Figure 4, it can be seen that TYPE A had a relatively consistent high score in every aspect. In all aspects, TYPE B sitting mats scored lower than TYPE A. TYPE C and TYPE D in visual and emotional aspects had high scores, but other aspects such as roughness, hardness, and thermal experienced a sharp decline. In the aspect of roughness and hardness, the TYPE $\mathrm{E}$ and $\mathrm{F}$ cushions scored high but were inversely proportional to the scores on the visual aspect, which were far low. On the thermal and emotional aspects, TYPE $\mathrm{E}$ and $\mathrm{F}$ experienced an increase and decrease that was not too drastic.

Apart from roughness, hardness, and thermals, other aspects were used to assess the comfort level of sitting on the floor while eating, namely visuals and emotions. Visually, the appearance of biocomposite seating was superior to existing seating because it was attractive and gave a natural and traditional impression. Hence, it influenced respondents to recommend others to experience the sitting experience. Evaluation of positive and negative emotions on the sitting mat also reflected the comfort level of the respondent sitting on the floor. High positive emotions indicated a high level of comfort and vice versa.

In contrast to the research conducted by Scilingo 
[10], who closed the eyes of the respondent in testing touch, this study invited respondents to open their eyes because it was related to eating. In addition, this study examined the visual stimulus of the seat material whether it affected the comfort of sitting on the floor while eating. The result is that the visual stimulus affects the perceived comfort of sitting and its effect on the atmosphere of the restaurant space. Visual perceives faster than touch, so it is essential in sustaining eating activities.

\section{CONCLUSION}

Based on the analysis and discussion previously disclosed, it is known that the pine needles biocomposites seating has an influence on the touch comfort for eating in a restaurant. Of the six TYPEs tested, the pine needles biocomposites type that the respondents felt the most comfortable with was TYPE A, a pine needles biocomposite material with a density of $0.05 \mathrm{gr} / \mathrm{cm} 3$. A net covers its surface because most respondents feel safe and convenient with the texture. The surface and level of softness of this seat cushion can accommodate prolonged sitting postures and does not interfere with eating activities. Another case with the high density and rough surface texture finishing (original biocomposite texture) causes a decrease in comfort level when eating and sitting on the floor. This is evidenced by the low comfort rating on the TYPE D seat cover. In addition, the thermal conditions are not good because the circulation of body heat flow on the material is not smooth, causing the user to feel hot, so it disturbs the comfort of sitting on the floor as felt by respondents on the TYPE E and F sitting mats.

This research on the use of biocomposite materials serves as an alternative material for interior elements, especially on the floor as a sitting mat. It is hoped that this material innovation can provide positive new experiences in the world of design. Doing this research will indirectly raise the culture of eating sitting on the floor with a new sensation of experience for restaurant entrepreneurs. Not only can it be applied to eating in a restaurant, but the research object can be applied in many activities, such as relaxing in the family room, reading books in the library, performing yoga, and many more.

Two factors are lacking in this research. First, this research still refers to the assumption of water as the raw materials in making biocomposites. This has an impact on the less precise material density. Future studies need to test the moisture content of the raw materials before making composites. Second, the application of treatment for surface finishing of biocomposite pine needles in this study still has the potential to break or come off when exposed to strong friction or movement. This study has used net textiles as one of the finishes to reduce this risk because it still visually shows biocomposite material, creates a flatter surface texture, and has a flexible character. Therefore, it can adjust the body pressure on the object. However, finishing with a net has not been able to maintain the biocomposite from fungi and insects. Thus, further research is needed regarding special treatments that can keep biocomposites strong but still elastic enough.

\section{ACKNOWLEDGEMENTS}

This research experiment was conducted with facility support from the Interior Design Study Program - FSRD ITB, ITB Postgraduate School, and Roemah Kopi. Therefore, the researchers would like to express their gratitude to the institutions.

\section{REFERENCES}

[1] M. Sisson, Floor Living: Do You Spend Enough Time on the Ground?, https://www.marksdailyapple.com/floor-livingdo-you-spend-enough-time-on-the-ground/, (12 October 2017).

[2] M. Permanasari, Hands and Chopsticks, How to Eat: A Comparative Study of Javanese and Japanese Eating Culture and Utensil Designs, in: Journal of the International Center for Cultural Resource Studies, 1, 2015, pp. 21-51.

[3] N. Sayuti, C. Montana-Hoyos, E. Bonollo, A Study of Furniture Design Incorporating Living Organisms with Particular Reference to Biophilic and Emotional Design Criteria, in: Academic Journal of Science, 4(1), 2015, pp.75106.

[4] H. Lilholt, J.M. Lawther, Natural organic fibres, in: Comprehensive composite materials, 1(10), 2000, pp. 303-325.

[5] S.E. Hänel, T. Dartman, R. Shishoo, Measuring methods for comfort rating of seats and beds, in: International Journal of Industrial Ergonomics, 20(2), 1997, pp. 163-172

[6] S. Motavalli, F. Ahmad, Measurement of seating comfort, in: Computers \& industrial engineering, 25(1-4), 1993, pp. 419-422.

[7] W. M. B. Tiest, Tactual perception of material properties, in: Vision research, 50(24), 2010, pp. 2775-2782. 
[8] G.W. Hewes, World distribution of certain postural habits, in: American Anthropologist, 57(2), 1955, pp. 231-244.

[9] D. Wiyancoko, Initiating Artifact Design as Cultural Product Development in Indonesia, in: Kanazawa Cultural Resources Studies, (3), 2014.

[10] E.P. Scilingo, M. Bianchi, G. Grioli, A. Bicchi, Rendering softness: Integration of kinesthetic and cutaneous information in a haptic device, in: IEEE Transactions on Haptics, 3(2), 2010, pp. 109-118.

[11] P. Desmet, Product emotion, In: H. N. J. Schifferstein \& P. Hekkert (Eds.), Product Experience- A multidisciplinary approach, Elsevier Science, 2007, pp. 379-397. 